\title{
Filter Cake Oil-Wax as Raw Material for the Production of Biodiesel: Analysis of the Extraction Process and the Transesterification Reaction
}

\author{
L. Casas, ${ }^{1}$ Y. Hernández, ${ }^{2}$ C. Mantell, ${ }^{1}$ N. Casdelo, ${ }^{2}$ and E. Martinez de la Ossa ${ }^{1}$ \\ ${ }^{1}$ Department of Chemical Engineering and Food Technology, Faculty of Science, International Agrifood Campus of Excellence (ceiA3), \\ University of Cadiz, Puerto Real, 11510 Cadiz, Spain \\ ${ }^{2}$ Department of Chemistry, Faculty of Chemistry and Pharmacy, Central University of Las Villas, Santa Clara, 50100 Villa Clara, Cuba
}

Correspondence should be addressed to L. Casas; lourdes.casas@uca.es

Received 11 December 2014; Accepted 23 February 2015

Academic Editor: Veera Gnaneswar Gude

Copyright (C) 2015 L. Casas et al. This is an open access article distributed under the Creative Commons Attribution License, which permits unrestricted use, distribution, and reproduction in any medium, provided the original work is properly cited.

\begin{abstract}
The viability of using the waste obtained in the manufacture of sugar from sugarcane for the production of biodiesel has been analyzed. Two fundamental stages are necessary to obtain biodiesel; the first stage is the extraction process from the waste oil materials and the second is the transesterification reaction. Four techniques, Soxhlet, orbital shaker extraction, ultrasonic-assisted extraction, and supercritical fluid extraction, have been analyzed. For Soxhlet, orbital shaker extraction, and ultrasonic-assisted extraction, the organic solvent (hexane) was maintained for all experiment. In supercritical fluid extraction two solvents were evaluated: pure $\mathrm{CO}_{2}$ and mixtures of $\mathrm{CO}_{2}$ and $5 \%(\mathrm{v}: \mathrm{v})$ methanol. The reaction kinetics of the transesterification reaction with an acidic catalyst and a basic catalyst were analysed. The results show that the supercritical extraction process produces a better product for the subsequent transesterification reaction. This finding is attributed to the high selectivity of carbon dioxide in the recovery of fatty acids and triglycerides in comparison with other solvents.
\end{abstract}

\section{Introduction}

Over many years an increasing number of researchers have shown that bioconversion of the biomass from agroindustrial wastes for the production of fuels and chemicals has the potential to change the world economically, socially, and environmentally [1-4]. As a consequence, research related to agricultural wastes is intensifying with the aim of evaluating the potential of this approach for recycling and to reduce the need for landfill.

Sugar from sugarcane (Saccharum officinarum) represents $65-70 \%$ of the world production of sugar and its production is mainly located in developing countries [5]. The production process requires high amounts of steam and electricity at the different stages and generates important quantities of residues. Significant amounts of byproducts are formed during the production of sugar from sugarcane. The byproducts of the sugar industry can be classified by the stages in which they are formed: those that originate during harvesting (agricultural stage) are tops and straw, whereas those that are formed during the industrial process include filter cake, molasses, and bagasse (Figure 1) [6]. A proportion of these byproducts can be used for the production of alcohol and they can also be used as a fuel to produce steam and electricity for the sugarcane industry.

The sugarcane also gives rise to saccharides along with intermediate and final products. These products can be used not only in farming but also in the food, chemical, and pharmaceutical industries. The lignocellulosic complex has the potential to provide fuel in solid, liquid, or gaseous forms or it can be used for electricity generation. Products such as cellulose, paper, furfural, boards, and other materials can generally be transformed into products of high added value [7]. Wastewater from the cane processing industry can be of economic use through biogas production and ferti-irrigation [8]. However, despite the uses outlined above, a considerable amount of waste still requires disposal. Therefore, there is considerable economic interest in the development of 


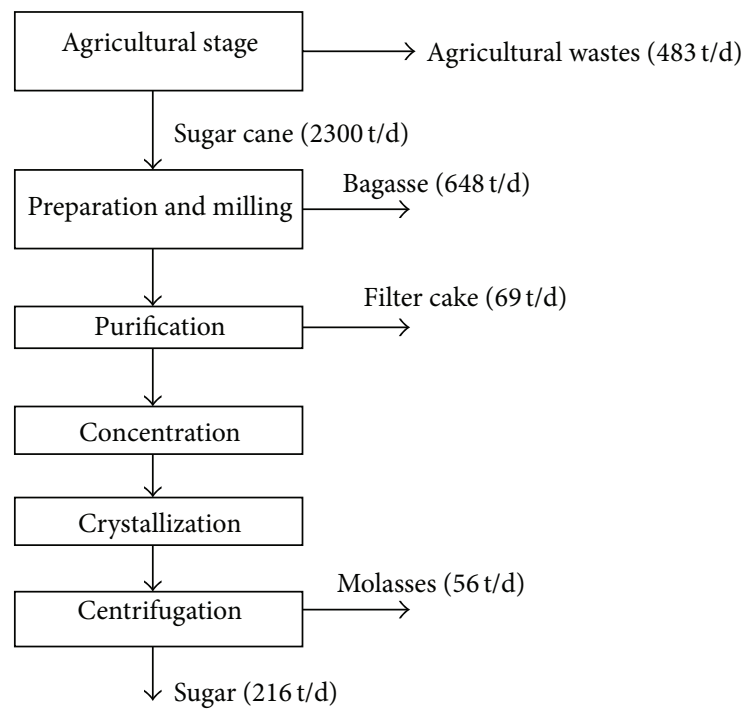

FIGURE 1: Products and byproducts of the sugar industry.

technology and processes for the effective exploitation of these wastes [9].

A major residue of the sugar production is filter cake, the residue from cane juice filtration. The filter cake is a dark solid fibrous residue that is extracted from the final process in the manufacture of sugar from sugarcane. The composition of the filter cake is estimated to be approximately $10-14 \%$ wax, oil, and resin, $12-16 \%$ protein, $8-12 \%$ ash, $3-5 \% \mathrm{P}_{2} \mathrm{O}_{5}$, $2.5 \% \mathrm{CaO}, 10-14 \%$ saccharose and reductive carbohydrates, $18-25 \%$ cane core, and $25-35 \%$ other materials. The filter cake usually has a high percentage of water, which is estimated to be in the range $75-77 \%$, meaning that the dry material represents approximately $23-25 \%[10,11]$.

Filter cake causes significant pollution, and in several sugar factories it is considered a waste, posing problems of management and final disposal. George et al. [5] have studied the opportunities of filter cake (and bagasse) and experimentally studied the use of filter cake as fuel at the sugar factory. Filter cake may, for example, be used as a fertilizer/soil improver directly applied on the fields or after composting. During its decomposition, it generates, however, an acid leachate and emits significant amounts of greenhouse gases. Moreover, the experimental part of the paper shows that blends of filter cake with bagasse can be combusted in industrial boilers in sugar factories, and that loose, nonvitrified ashes with a similar appearance as bagasse ash are obtained. This results in lower volumes and masses of residues to be transported, so that transportation costs are reduced. Moreover, it gives a new economic value to the filter cake and reduces its environmental impact. When all filter cakes would be combusted blended with bagasse, about $25 \%$ more ash would be obtained than for bagasse and the trace element composition would comply with the regulatory limits for use as fertilizer/soil improver.

The principal product obtained from the filter cake is the sugarcane crude wax. The industrial process for the extraction of sugarcane crude wax from filter cake is heptane extraction. Three fractions are usually separated in this process [12]:

(i) $\operatorname{wax}(55-62 \%)$,

(ii) oil (25-31\%),

(iii) resin (10-13\%), volatiles (0.8-2\%), and insoluble (0.7$0.8 \%)$.

The separation consists of different successive multiple steps and enables the initial fractionation of the resin compounds followed by the separation in a second step of the oils and refined wax. The biological effects of active compounds extracted from sugarcane crude wax, such as long chain nalcohols, fatty acids, or ethanolic extracts, have been reported by various groups to have applications in atherosclerotic vascular coronary heart disease [13] and other therapeutic applications [14].

Taking into account the current trend in the provision of new sources for the production of biofuels, the use of filter cake as a raw material in production of bio-oils seems to be feasible for the high concentration in oils. Due to the complexity of this product, it is important to analyse the extraction process in order to determine the best process for the subsequent transesterification stage [15]. The extraction process must be highly selective and, wherever possible, environmentally friendly. Numerous approaches for the recovery of oil from different raw materials have been published in the literature. In recent years, the ultrasound-assisted extraction (UAE) and the supercritical fluid extraction (SFE) techniques have been used in this kind of process.

UAE is a good choice in comparison with the more traditional approaches due to its high efficiency, low energy requirements, and low solvent consumption. This technique has been applied in the extraction of bioactive compounds from plants [16-18] and other products [19]. The improvement in the extraction process on using ultrasound is related to the destruction of the cell walls, the reduction of the particle size, and the enhancement of mass transfer through the cell wall due to the collapse of bubbles produced by cavitation [20].

In SFE, carbon dioxide is used as the solvent in the majority of cases. This is an advanced technology that has a low environmental impact due to the advantages of $\mathrm{CO}_{2}$ as a solvent, that is, low toxicity, low cost, and easy separation from extracts [21]. The use of $\mathrm{CO}_{2}$ gives an added advantage in terms of quality, as extracts do not suffer excessive heating, which may destroy thermally unstable compounds. $\mathrm{CO}_{2}$ has a very high selectivity and is a good solvent for low molecular weight and nonpolar products. In some cases, a small amount of cosolvent can be added to modify the polarity in an effort to increase the effectiveness of this solvent.

As far as the extraction of sugarcane waste is concerned, de Lucas et al. studied the supercritical extraction of long chain $\mathrm{n}$-alcohols from sugarcane crude wax. The results were compared to those obtained using the existing multistage industrial organic solvent refining process. The quality of the supercritical extract was considerably higher on using SFE due to the higher $\mathrm{n}$-alcohol purity, $78.24 \%(\mathrm{w} / \mathrm{w})$, compared to the organic solvent extraction yield, $22.00 \%(\mathrm{w} / \mathrm{w})[15]$. 
In the work described here, different extraction methods were evaluated to obtain oil-wax from filter cake. Conventional methods are compared with UAE and SFE in terms of the best extraction yields. The viability of the product for the production of bio-oils was assessed by carrying out the transesterification process with methanol using an acidic or basic catalyst.

\section{Materials and Methods}

2.1. Materials and Chemicals. Filter cake was collected in 2009 and was provided by the Ifrain Alfonso Sugar Mill, Villa Clara, Cuba. The sample was dried at room temperature to constant weight. Carbon dioxide was obtained from Abello-Linde S.A. (Barcelona, Spain); the standard for methyl esters was purchased from Sigma-Aldrich (Steinheim, Germany). The other reagents (hexane, methanol, toluene, orthophosphoric acid, hydrochloric acids, and potassium hydroxide) were obtained from Panreac (Barcelona, Spain). The analytical standards were obtained from Sigma-Aldrich with $1 \%$ of impurities.

\subsection{Extraction of Oil-Wax from Filter Cake}

2.2.1. Soxhlet Extraction. Soxhlet extraction was carried out using cellulose thimbles containing $150 \mathrm{~g}$ of sample. The extraction was carried out using $250 \mathrm{~mL}$ of hexane for $24 \mathrm{~h}$, at atmospheric pressure [22]. The solvent was concentrated under reduced pressure in a temperature-controlled bath at $40^{\circ} \mathrm{C}$.

2.2.2. Orbital Shaker Extraction. The sample and hexane were placed in capped flasks (solvent-to-solid ratios, 3:1, 5:1, $7: 1$, and $9: 1$ weight/volume) and maintained at $150 \mathrm{rpm}$ and $50^{\circ} \mathrm{C}$ for $10 \mathrm{~h}$ in an orbital incubator shaker, at atmospheric pressure (HS 501 orbital shaker, IKA, Staufen, Germany) [22]. The extracts were filtered and the solvent was removed under reduced pressure with a temperature-controlled bath at $40^{\circ} \mathrm{C}$.

2.2.3. Ultrasound-Assisted Extraction. Extractions were carried out in an Elmasonic S 300 ultrasonic bath at atmospheric pressure. The solvent-to-solid ratio used was $7: 1$ and the solvent was hexane [17]. Two different procedures were employed. In the first procedure the sample/solvent mixture was placed in the ultrasonic bath for $3 \mathrm{~h}$ with continuous sonication and in the second procedure the mixture was alternately agitated vigorously in ultrasonic bath for $15 \mathrm{~min}$ and then left to stand for $15 \mathrm{~min}$ without stirring for a total time of $3 \mathrm{~h}$. The UAE generates an increase in the temperature of the solvent. For this reason, it may be adequate to realize a program of exposure to the ultrasound in order to avoid this increase. This is the expectative of both methods.

The resulting extracts were treated in the same way as the extract obtained by orbital shaker extraction.

\subsubsection{Supercritical Fluid Extraction. Extractions were carried} out in SFE equipment from Thar Technology (Pittsburgh, PA, USA, model SF2000) with a $2 \mathrm{~L}$ extraction vessel and two high-pressure pumps, one for carbon dioxide and the other

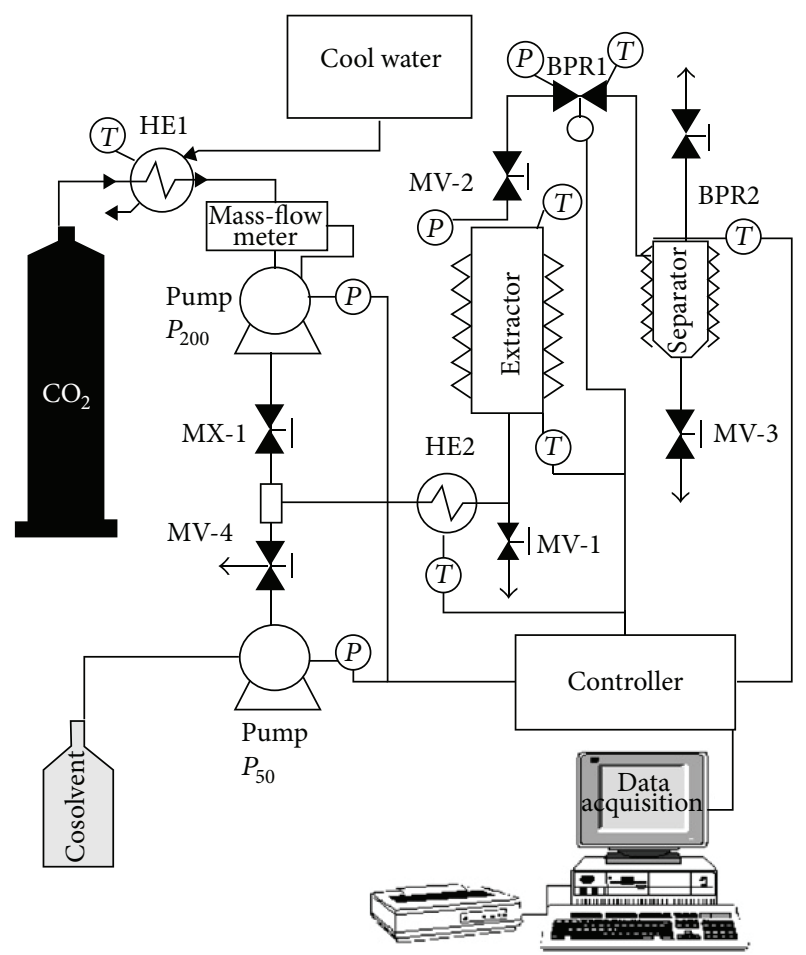

FIGURE 2: Schematic diagram of the equipment used for the SFE.

for the cosolvent (Figure 2) [23]. Several sets of conditions for pressure and temperature were tested, namely, pressures of 200 and 400 bar and temperatures of 35 and $55^{\circ} \mathrm{C}$. The extraction solvent was either pure $\mathrm{CO}_{2}$ or mixtures of $\mathrm{CO}_{2}$ and $5 \%(\mathrm{v}: \mathrm{v})$ methanol.

The operating methodology involved loading the extraction cartridge with approximately $130 \mathrm{~g}$ of the sample, which had previously been homogenized in order to maintain a constant apparent density in all experiments. The extracts were collected in cyclonic separator and transferred to glass bottles, which were stored at $4^{\circ} \mathrm{C}$ with the exclusion of light. The experimental procedure was explained in a more detailed form in a previous work [23].

The experiments for each extraction were carried out in triplicate in order to evaluate the variability of the measurements. The results are shown as the average of all the independent analyses with a reproducibility of approximately $8.6 \% \mathrm{CV}$ (coefficient of variation).

\subsection{Properties of Extracts}

2.3.1. Fatty Acids Composition. The fatty acid (FA) constituents were analysed by gas chromatography (GC) (Agilent Technologies model $6890 \mathrm{~N}$ ) with a capillary column (SupraWAX-280, $30 \mathrm{~m}$ length $\times 0.25 \mathrm{~mm}$ internal diameter $\times$ $0.25 \mu \mathrm{m}$ thickness), automatic injection, and a flame ionization detector (FID).

The FAME extraction of the resulting mixture was carried out by adding $2 \times 2 \mathrm{~mL}$ of $\mathrm{n}$-hexane and then shaking the mixture vigorously automatically in a vortex for $30 \mathrm{~s}$. The sample was stored for $5 \mathrm{~min}$ in order to allow a bilayer to 
form. The clear upper layer, which contained the FAME, was injected $(10 \mu \mathrm{L})$ into the gas chromatograph using an internal standard method.

The injector and detector temperatures were 200 and $275^{\circ} \mathrm{C}$, respectively. The oven temperature was set at $90^{\circ} \mathrm{C}$ and this was increased at a heating rate of $30^{\circ} \mathrm{C} / \mathrm{min}$ up to $192^{\circ} \mathrm{C}$. Immediately, the rate of heating was changed to $2^{\circ} \mathrm{C} / \mathrm{min}$ until the temperature of $195^{\circ} \mathrm{C}$ is reached. This temperature is held at this point for $5 \mathrm{~min}$ and finally increased at a heating rate of $2^{\circ} \mathrm{C} / \mathrm{min}$ up to the final temperature of $211^{\circ} \mathrm{C}$ [24]. The analysis was carried out in triplicate.

The FAME components were identified by comparison of their retention times with those of the commercial standards. Heptadecanoic acid was used as internal standard. The calibration curves were as follows:

Palmitic acid C16:0

$$
A=-0.023+5.91 C \quad R^{2}=0.9996,
$$

Palmitoleic acid C16:1 n-7

$$
A=0.029+5.02 C \quad R^{2}=0.9943,
$$

Stearic acid C18:0

$$
A=0.024+5.26 C \quad R^{2}=0.9999,
$$

Oleic acid C18:1 n-7

$$
A=0.024+5.18 C \quad R^{2}=0.9936,
$$

Linoleic acid C18:2 n-6

$$
A=0.025+5.36 C \quad R^{2}=0.9995,
$$

Linolenic acid C18:3 n-6

$$
A=0.029+5.09 C \quad R^{2}=0.9994,
$$

where $A$ is the area expressed in $\mathrm{pA}$ and $C$ is the concentration expressed in $\mathrm{g} / \mathrm{L}$.

2.3.2. Acid Value. The acid values of the oils obtained under different conditions were analyzed according to a normalized determination [25]. Acidity index is the mass, expressed in $\mathrm{mg}$, of potassium hydroxide that is necessary to neutralize free fatty acid present in $1 \mathrm{~g}$ of sample. It is common to represent this value as the percentage of oleic acid, which is the most abundant fatty acid.

2.4. Transesterification for Biodiesel Conversion from OilWax. Different methanol-to-oil ratios in terms of percentage volume $(1: 3,1: 9,1: 12,1: 39$, and $1: 100)$ and reaction times were used to study the reaction of biodiesel from oil-wax. The progress of the reaction was monitored by measuring the transformed FAME [26].

Prior to the catalysed transesterification, the pretreatment proposed by Samaram et al. [16] was carried out in order to eliminate the wax-oil traces of organic matter and to lower the acid value. In this stage a mixture of crude wax-oil, methanol, orthophosphoric acid, and toluene was stirred at a constant speed of $450 \mathrm{rpm}$ and $66^{\circ} \mathrm{C}$ for $0.5-4 \mathrm{~h}$. One litre of oil was mixed with $350 \mathrm{~mL}$ of methanol, $5 \mathrm{~mL}$ of toluene, and $5 \mathrm{~mL}$ of orthophosphoric acid as a reagent. Toluene helps to dissolve the organic matter along with methanol and separates it from the neat oil along with other impurities. The product from the first stage was allowed to settle for $1 \mathrm{~h}$ and complete phase separation was assessed visually. The upper layer, which contained the methanol/water fraction, organic matter, gum, toluene, and other impurities, was separated from the lower layer. The lower layer was the raw material for the acid- and base-catalysed transesterifications [27].

2.4.1. Acid-Catalysed Transesterification. Hydrochloric acid $(37.7 \%)$ was used as a catalyst in the acid-catalysed transesterification. The product of the previous stage was mixed with $5 \mathrm{~mL}$ hydrochloric acid ( $0.1 \% \mathrm{v} / \mathrm{v}$ in methanol) and different volumes of methanol. The stirring speed was maintained at $350 \mathrm{rpm}$ and the reaction temperature was $65^{\circ} \mathrm{C}$. The progress of the reaction was monitored at times of $15,30,45,60,120$, $180,240,300$, and $360 \mathrm{~min}$.

2.4.2. Base-Catalysed Transesterification. Potassium hydroxide ( $1 \%$ in methanol) was used as a catalyst in the basecatalysed transesterification. The catalyst $(\mathrm{KOH})$ was dissolved in methanol with vigorous stirring. The product of the previous stage was transferred to the reactor. The final mixture was stirred vigorously at $350 \mathrm{rpm}$ for $4 \mathrm{~h}$ at $100^{\circ} \mathrm{C}$. The second stage was similar to that described for the acidcatalysed transesterification.

Successful transesterification reactions produced two liquid phases: ester and crude glycerine. Crude glycerine is the heavier liquid and this is collected at the bottom of the vessel after several hours of settling. Phase separation could be observed within $10 \mathrm{~min}$ and was complete within $2 \mathrm{~h}$. The top ester layer was separated and purified using warm water. After washing, the final product was heated up to $70^{\circ} \mathrm{C}$ for $15 \mathrm{~min}$ under vacuum in order to remove water and then stored for further use.

\section{Results and Discussion}

3.1. Extraction Process. The extraction yields obtained by Soxhlet extraction, orbital shaker extraction (OSE), and ultrasound-assisted extraction (UAE) are shown in Figure 3. OSE was carried out at four different solvent-to-solid ratios for $10 \mathrm{~h}$. The best results were obtained with a solventto-solid ratio of $7: 1$. Higher solvent-to-solid ratios led to similar extraction yields but with a higher consumption of solvent. The results obtained by UAE with alternate intervals of shaking and standing were comparable to the results obtained by OSE with a solvent-to-solid ratio of $7: 1$. The UAE in continuous mode led to lower extraction yields. This behaviour can be attributed to loss of solvent due to the increase in the solvent temperature. The Soxhlet extraction gave the best extraction yields. The differences can be mainly explained by temperature effects. Soxhlet extraction is carried 
TABLE 1: Fatty acid concentrations and acid values of the extracts obtained by Soxhlet, OSE, UAE, and SFE.

\begin{tabular}{|c|c|c|c|c|c|c|}
\hline & & & omposit & & & \\
\hline & $\begin{array}{c}\text { Palmitic } \\
\text { (C16:0) }\end{array}$ & $\begin{array}{l}\text { Stearic } \\
(\mathrm{C} 18: 0)\end{array}$ & $\begin{array}{l}\text { Oleic } \\
\text { (C18:1) }\end{array}$ & $\begin{array}{l}\text { Linoleic } \\
\text { (C18:2) }\end{array}$ & $\begin{array}{c}\text { Linolenic } \\
(\mathrm{C} 18: 3)\end{array}$ & Acid value \\
\hline Soxhlet & 11.5 & 24.5 & 2.38 & 5.28 & 6.40 & 6.55 \\
\hline OSE $(3: 1)$ & 3.3 & 5.6 & n.d & 0.4 & 1.6 & 15.93 \\
\hline OSE $(5: 1)$ & 9.4 & 15.7 & 7.5 & 17.6 & 15.7 & 12.18 \\
\hline OSE $(7: 1)$ & 10.7 & 20.2 & n.d & n.d & 5.8 & 12.19 \\
\hline OSE $(9: 1)$ & 12.1 & 27.3 & n.d & 0.8 & 3.9 & 13.57 \\
\hline UAE (1) & 7.6 & 17.9 & n.d & 0.1 & 2.5 & 8.46 \\
\hline UAE (2) & 3.40 & 8.96 & 0.4 & 0.5 & 1.9 & 4.43 \\
\hline $\mathrm{SFE} \mathrm{CO}{ }_{2}$ & & & & & & \\
\hline $200 \mathrm{bar} / 35^{\circ} \mathrm{C}$ & 75.09 & 38.79 & 143.07 & 160.66 & 21.65 & 19.35 \\
\hline $200 \mathrm{bar} / 55^{\circ} \mathrm{C}$ & 63.66 & 44.55 & 144.16 & 131.66 & 6.8 & 26.02 \\
\hline $400 \mathrm{bar} / 35^{\circ} \mathrm{C}$ & 106.30 & 77.10 & 226.59 & 205.29 & 10.85 & 22.21 \\
\hline $400 \mathrm{bar} / 55^{\circ} \mathrm{C}$ & 83.69 & 79.19 & 175.37 & 162.46 & 13.7 & 24.45 \\
\hline $\mathrm{SFE} \mathrm{CO} \mathrm{CO}_{2} /$ methan & & & & & & \\
\hline $200 \mathrm{bar} / 35^{\circ} \mathrm{C}$ & 14.51 & 23.54 & 5.31 & 4.44 & 2.65 & 29.44 \\
\hline $200 \mathrm{bar} / 55^{\circ} \mathrm{C}$ & 15.89 & 26.58 & 6.00 & 5.01 & 2.70 & 22.41 \\
\hline $400 \mathrm{bar} / 35^{\circ} \mathrm{C}$ & 23.63 & 37.51 & 5.64 & 5.53 & 3.87 & 11.58 \\
\hline $400 \mathrm{bar} / 55^{\circ} \mathrm{C}$ & 25.13 & 43.65 & 5.36 & 5.72 & 3.47 & 20.57 \\
\hline
\end{tabular}

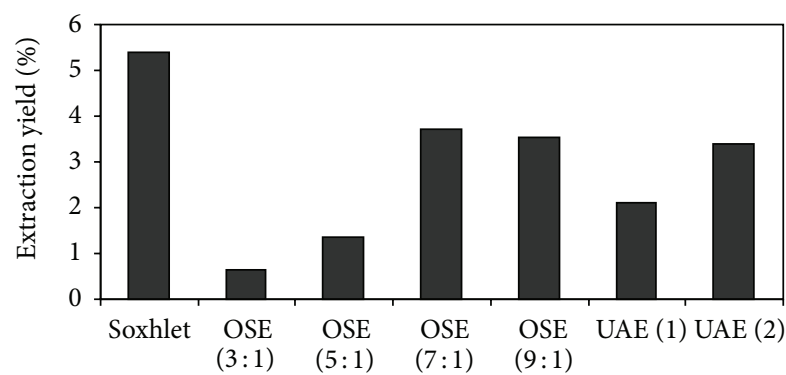

FIGURE 3: OSE, orbital shaker extraction. UAE, ultrasound-assisted extraction. UAE (1), continuous ultrasound-assisted extraction for 3 h. UAE (2), ultrasound-assisted extraction with intervals.

out at the maximum temperature possible (i.e., boiling point of the solvent), while the other methods are carried out at room temperature.

The fatty acid compositions in the different extracts obtained by Soxhlet extraction, OSE, and UAE are shown in Table 1 . The results are expressed as mg FAME/g extract. Stearic acid (C18:0) and palmitic acid (C16:0) were the predominant fatty acids in all tests. The fatty acids content was relatively low on using these techniques. For this reason, it is important to investigate more selective extraction methods in an effort to increase the concentration of fatty acids. The acid values are also presented in Table 1 . Higher acid values imply higher selectivity in the extraction of fatty acids and the highest values were obtained on using OSE as the extraction method.

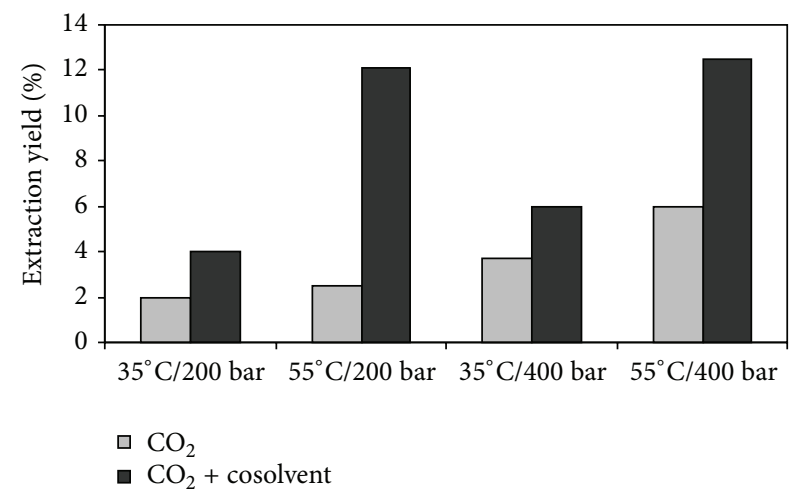

FIGURE 4: Extraction yields obtained using SFE under different temperature/pressure conditions.

In order to compare the results with those of the conventional extraction and UAE methods, supercritical fluid extraction was investigated. This technique is associated with shorter extraction times and reduced solvent consumption. The extraction process is facilitated due to increased analyte desorption and diffusion from the solid matrix. The extraction yields obtained by SFE with pure $\mathrm{CO}_{2}$ and a mixture of $\mathrm{CO}_{2}$ and $5 \%(\mathrm{v} / \mathrm{v})$ of methanol are shown in Figure 4.

In SFE the solvating power of the fluids can be adjusted by changing pressure and/or temperature and, in this way, a remarkably high selectivity can be achieved. Variations in the yields obtained under different conditions (pressure, 
temperature) are similar when the extractions are carried out with pure $\mathrm{CO}_{2}$ or $\mathrm{CO}_{2} /$ methanol. It can be seen from Figure 4 that, at a constant temperature, an increase in the pressure leads to an increase in the density of the SCF; that is, its solvating power becomes greater and greater quantities of substances are transferred to the supercritical $\mathrm{CO}_{2}$, which in turn means that the extraction process is favoured. An increase in temperature at constant pressure benefits the extraction process due to the increase in the vapour pressure of the substances extracted, a change that more than compensates for the decrease in the density of supercritical $\mathrm{CO}_{2}$.

The addition of a small amount of a liquid modifier can often significantly enhance the extraction efficiency [23]. The extraction yield increased on adding methanol. The best extraction yields were obtained at $55^{\circ} \mathrm{C}$ and 400 bar with $\mathrm{CO}_{2}$ and methanol. These results are better than those obtained by Soxhlet extraction.

The fatty acid composition obtained by SFE is different from those in the extracts obtained by Soxhlet extraction, OSE, and UAE (Table 1). In the case of SFE, linoleic acid (C18:2) and oleic acid (C18:1) are the predominant fatty acids in the extracts.

The behaviour outlined above can be attributed to the different selectivity for the extracted compounds and the method for the fatty acid determination. In the method employed the composition in fatty acids was analysed after a transesterification reaction with methanol under relatively harsh conditions. Finally, the FAME compounds were analysed by gas chromatography. The fatty acids could be present in a wide variety of compounds and the composition can vary depending on the family of compounds extracted. Fatty acids can be free, in a triglyceride or in a phospholipid. The fact that carbon dioxide is selective to triglycerides and free fatty acids may influence, and explain, the results obtained. The acid values obtained by SFE are also higher than those obtained by Soxhlet extraction, OSE, and UAE, thus confirming the hypothesis outlined above [22].

In cases where a cosolvent is added, the selectivity of the solvent decreases and, for this reason, the composition is similar to that obtained with conventional solvents. The acidity results shown in Table 1 indicate that the total amount of fatty acids obtained by SFE is greater for SFE with pure $\mathrm{CO}_{2}$. As mentioned above, the filter cake contains a wide variety of fats, waxy esters, free alcohols, sterols, and a resinous fraction that is mainly composed of calcium salts of heavy polyesters. Free alcohols and sterols are more suitable for extraction by $\mathrm{CO}_{2}$ and methanol and, for this reason, the concentration in fatty acids decreases on using this solvent mixture.

3.2. Transesterification Process. Once the extraction process had been analysed, the results of the transesterification reaction were compared. From the results discussed in the previous section, SFE seems to be the best extraction method to use for the study of the transesterification. For this reason, the transesterification reaction was only carried out on the oils obtained by this extraction method. Nevertheless, in order to compare the results obtained with this oil, the transesterification of the oil obtained by Soxhlet extraction was also carried out. The comparison involved the use of two different catalysts in the reaction, namely, acid- and basecatalysed transesterifications.

A lower acid value $(<4 \mathrm{mg} \mathrm{KOH} / \mathrm{g})$ indicates a high quality vegetable oil. An increase in acid value should be taken as an indicator of oxidation of the oil, which may lead to gum and sludge formation in addition to corrosion. It can be observed from the results in Table 1 that the acid values of the wax-oils are above $4 \mathrm{mg} \mathrm{KOH} / \mathrm{g}$. Therefore, it was necessary to carry out an initial stage before the transesterification reaction in order to lower the acid value prior to optimising parameters such as methanol-to-oil ratio, reaction duration, and catalysed transesterification.

The amount of alcohol added to vegetable oil is one of the important factors that affect the conversion efficiency and the production cost of biodiesel. The conversion efficiency is defined as the yield of the process as a percentage. Stoichiometrically, the triglyceride/methanol molar ratio required is $1: 3$. However, in practice, this is not sufficient to complete the reaction. The amount of methanol required for transesterification is considered in terms of volumetric ratio. A higher amount of alcohol is required to drive the reaction to completion at a faster rate. In the work described here five ratios were tested $(1: 3,1: 8,1: 12,1: 39$, and $1: 100$ by volume).

The conversion efficiency in relation to the amount of alcohol in the acid-catalysed transesterification is shown in Figure 5. As the percentage of methanol was increased, the yield of biodiesel improved significantly and this increase was particularly marked on changing from a volume ratio of $1: 3$ to higher ratios. At ratios of $1: 100$ and $1: 39$ the amount of methanol was thought to be excessive and the conversion and time are similar to those obtained with a 1:12 ratio. On the other hand, a higher yield was obtained with a higher percentage of methanol but the energy required for the recovery of methanol increases correspondingly. Therefore, $1: 12$ is a suitable volume ratio because any further increase in this ratio does not give rise to a significant improvement in performance in terms of time or the conversion efficiency.

In order to achieve an effective interaction between the catalyst and the oil-wax during transesterification, it is essential that the components must be stirred well at a constant rate. It can be observed from Figure 5 that the yield of methyl ester increases with increasing reaction time. For the waxoil obtained by Soxhlet extraction and a volume ratio of $1: 100$, the transesterification reaction is complete at $60 \mathrm{~min}$. For volume ratios of $1: 39$ and $1: 12$, the transesterification reaction is complete at $120 \mathrm{~min}$. However, for the waxoil extracted by SFE at volume ratios of $1: 100,1: 39$, and $1: 12,100 \%$ conversion is obtained at $60 \mathrm{~min}$. However, the transesterification reaction of the sample corresponding to a volume ratio of $1: 8$ was reached at $120 \mathrm{~min}$. Therefore, a reaction time of $120 \mathrm{~min}$ is sufficient for the completion of the acid-catalysed transesterification for a ratio of $1: 8$ with SFE oil.

The conversion efficiency during the base-catalysed transesterification is represented in Figure 6. The maximum conversion did not exceed $85 \%$ for the reaction time studied. An increase in the volume ratio led to an increase in 

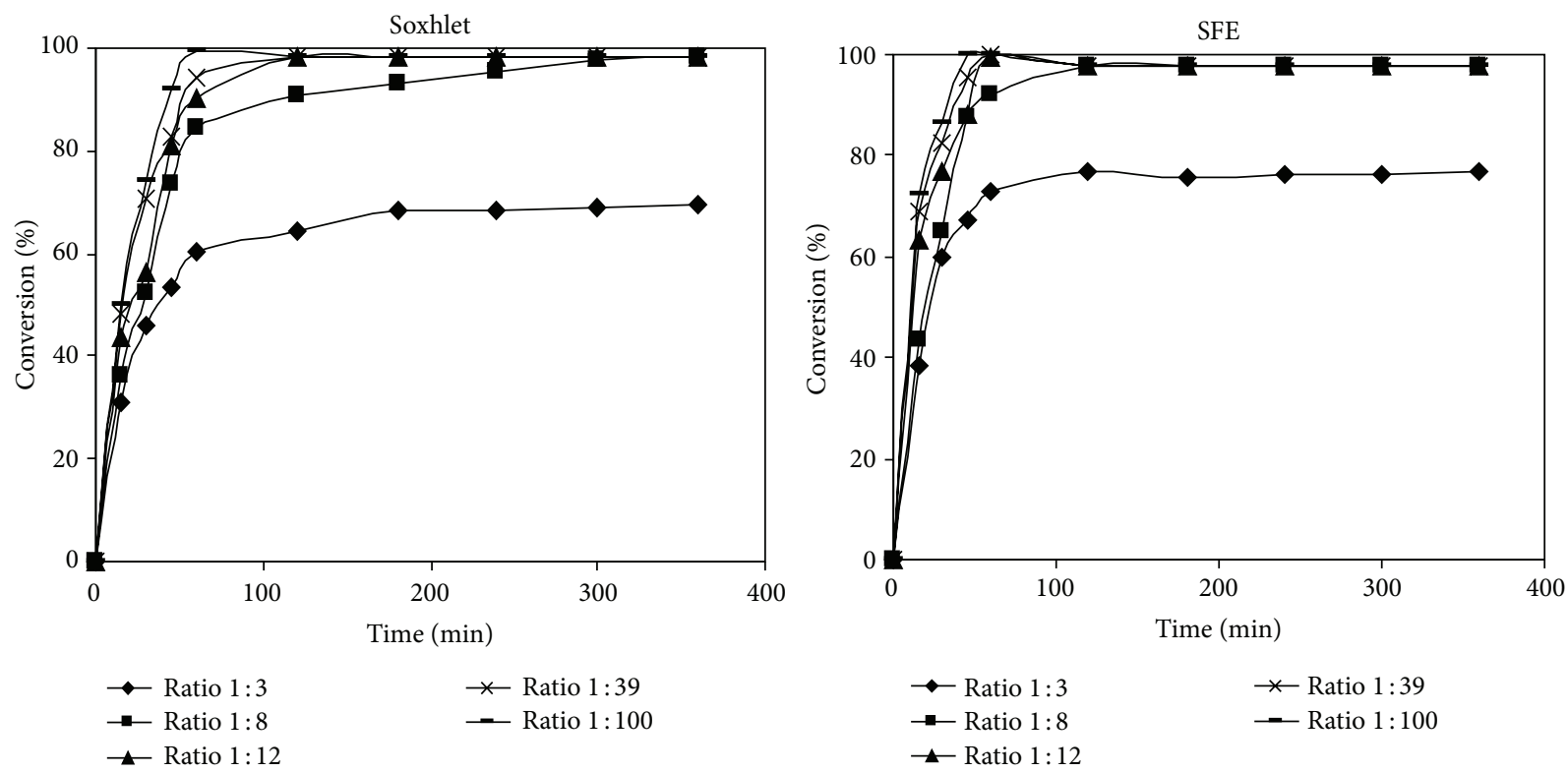

FIgURE 5: Acid-catalysed transesterification of oils obtained by Soxhlet extraction and by SFE with carbon dioxide at 400 bar and $35^{\circ} \mathrm{C}$.
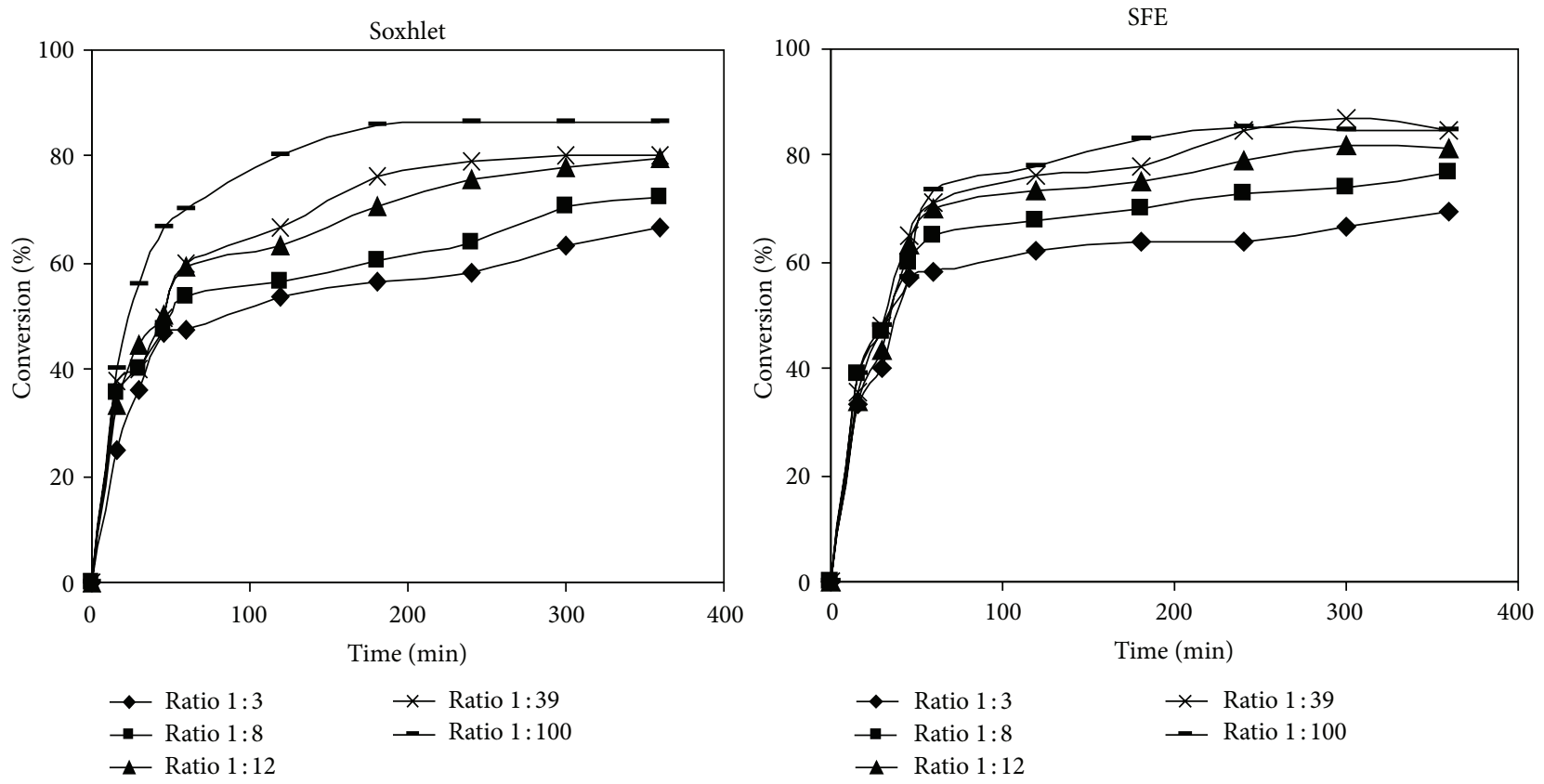

FIgURE 6: Base-catalysed transesterification of oils obtained by Soxhlet extraction and by SFE with carbon dioxide at 400 bar and $35^{\circ} \mathrm{C}$.

the conversion efficiency. However, as in the acid-catalysed process, the amount of methanol is excessive for ratios of $1: 100$ and $1: 39$ and the conversion in the time is similar to that achieved with a $1: 12$ volume ratio. Therefore, $1: 12$ is a suitable ratio because any increase in the ratio does not lead to any significant improvement in the conversion efficiency.

One limitation of the base-catalysed process is its sensitivity to both water and free fatty acids. Free fatty acids can react with the alkali to produce soaps and water. In the basecatalysed transesterification the presence of free fatty acids and water always has a negative effect since soap formation results, the catalyst is consumed, and the catalyst effectiveness is reduced. The presence of water has more marked negative effect than the free fatty acids [28] and the water content should therefore be kept below $0.06 \%$. The presence of water may be the cause of the decrease in conversion efficiency.

According to Freedman et al. [29], Liu et al. [30], and Mittelbach [31], the oil or fat used in alkaline transesterification reactions should contain no more than $1 \%$ free fatty acids (FFA), which is equivalent to $2 \mathrm{mg} \mathrm{KOH} / \mathrm{g}$ triglyceride. 
If the FFA level exceeds this threshold, saponification hinders separation of the ester from glycerine and reduces the yield and formation rate of FAME.

\section{Conclusions}

The results obtained in this study show that the SFE process, using carbon dioxide as solvent, enables the extraction of a product that is suitable for biodiesel production. The extraction yield obtained by SFE was not the highest, but the conversion achieved in the transesterification process was higher with this solvent. The best conditions for the SFE of the oil-wax were $55^{\circ} \mathrm{C}$ and 400 bar. These results open up the possibility of recovering waste from the sugarcane process for biofuel production. The acid-catalysed transesterification process provides the best conversions at lower times.

\section{Conflict of Interests}

The authors declare that there is no conflict of interests regarding the publication of this paper.

\section{Acknowledgment}

The authors thank the Spanish Ministry of Education and Science for funding Project CTQ2008-03336.

\section{References}

[1] D. E. Leiva-Candia, S. Pinzi, M. D. Redel-Macías, A. Koutinas, C. Webb, and M. P. Dorado, "The potential for agro-industrial waste utilization using oleaginous yeast for the production of biodiesel," Fuel, vol. 123, pp. 33-42, 2014.

[2] B. G. D. O. Maia, O. Souza, C. Marangoni, D. Hotza, A. P. N. De Oliveira, and N. Sellin, "Production and characterization of fuel briquettes from banana leaves waste," Chemical Engineering Transactions, vol. 37, pp. 439-444, 2014.

[3] G. di Giacomo and L. Taglieri, "Development and evaluation of a new advanced solid bio-fuel and related production process," International Journal of Renewable Energy Research, vol. 3, no. 2, pp. 255-260, 2013.

[4] A. L. F. Santos, D. U. Martins, O. K. Iha, R. A. M. Ribeiro, R. L. Quirino, and P. A. Z. Suarez, "Agro-industrial residues as low-price feedstock for diesel-like fuel production by thermal cracking," Bioresource Technology, vol. 101, no. 15, pp. 6157-6162, 2010.

[5] P. A. O. George, J. J. C. Eras, A. S. Gutierrez, L. Hens, and C. Vandecasteele, "Residue from sugarcane juice filtration (filter cake): energy use at the sugar factory," Waste and Biomass Valorization, vol. 1, no. 4, pp. 407-413, 2010.

[6] A. M. Contreras, E. Rosa, M. Pérez, H. van Langenhove, and J. Dewulf, "Comparative Life Cycle Assessment of four alternatives for using by-products of cane sugar production," Journal of Cleaner Production, vol. 17, no. 8, pp. 772-779, 2009.

[7] P. A. Filho and O. Badr, "Biomass resources for energy in NorthEastern Brazil," Applied Energy, vol. 77, no. 1, pp. 51-67, 2004.

[8] W. Zhu, X. Cheng, C. Lin, J. Liang, Z. Cui, and S. Yang, "Biogas made from high concentrate wastewater in sugarcane and cassava distilleries," in Proceedings of the International Conference on Mechanic Automation and Control Engineering (MACE '10), pp. 5167-5173, June 2010.
[9] B.-G. Zhang, G.-T. Li, T.-S. Shen, J.-K. Wang, and Z. Sun, "Changes in microbial biomass $\mathrm{C}, \mathrm{N}$, and $\mathrm{P}$ and enzyme activities in soil incubated with the earthworms Metaphire guillelmi or Eisenia fetida," Soil Biology and Biochemistry, vol. 32, no. 14, pp. 2055-2062, 2000.

[10] R. Kumar, D. Verma, B. L. Singh, and U. Kumar, "Composting of sugar-cane waste by-products through treatment with microorganisms and subsequent vermicomposting," Bioresource Technology, vol. 101, no. 17, pp. 6707-6711, 2010.

[11] A. D. Santiago, R. Rossetto, W. De Mello Ivo, and S. Urquiaga, "Sugarcane," in Issues in Environmental Science and Technology, pp. 77-103, 2010.

[12] R. Suarez and R. Morín, "Caña de azúcar y sostenibilidad: enfoques y experiencias cubanas," Morín2, 2014, http://www.uv .mx/personal/tangarcia/files/2014/02/A6_Caña_en_CUBA.pdf.

[13] S. R. Abbas, S. D. Ahmad, S. M. Sabir et al., "Antioxidant activity, repair and tolerance of oxidative DNA damage in different cultivars of sugarcane (Saccharum officinarum) leaves," Australian Journal of Crop Science, vol. 7, no. 1, pp. 40-45, 2013.

[14] J. M. Duarte-Almeida, A. V. Novoa, A. F. Linares, F. M. Lajolo, and M. I. Genovese, "Antioxidant activity of phenolics compounds from sugar cane (Saccharum officinarum L.) juice," Plant Foods for Human Nutrition, vol. 61, no. 4, pp. 187-192, 2006.

[15] A. de Lucas, A. García, A. Alvarez, and I. Gracia, "Supercritical extraction of long chain $n$-alcohols from sugar cane crude wax," The Journal of Supercritical Fluids, vol. 41, no. 2, pp. 267-271, 2007.

[16] S. Samaram, H. Mirhosseini, C. P. Tan, H. M. Ghazali, S. Bordbar, and A. Serjouie, "Optimization of ultrasound-assisted extraction of oil from papaya seed by response surface methodology: oil recovery, radical scavenging antioxidant activity, and oxidation stability," Food Chemistry, vol. 172, pp. 7-17, 2015.

[17] L. C. Cardoso, C. M. Serrano, E. T. Quintero, C. P. López, R. M. Antezana, and E. J. M. de la Ossa, "High pressure extraction of antioxidants from Solanum stenotomun peel," Molecules, vol. 18, no. 3, pp. 3137-3151, 2013.

[18] R.-E. Ghitescu, I. Volf, C. Carausu, A.-M. Buhlmann, I. A. Gilca, and V. I. Popa, "Optimization of ultrasound-assisted extraction of polyphenols from spruce wood bark," Ultrasonics Sonochemistry, vol. 22, pp. 535-541, 2015.

[19] M. D. Macías-Sánchez, C. Mantell, M. Rodríguez, E. M. de la Ossa, L. M. Lubián, and O. Montero, "Comparison of supercritical fluid and ultrasound-assisted extraction of carotenoids and chlorophyll a from Dunaliella salina," Talanta, vol. 77, no. 3, pp. 948-952, 2009.

[20] L. Paniwnyk, E. Beaufoy, J. P. Lorimer, and T. J. Mason, “The extraction of rutin from flower buds of Sophora japonica," Ultrasonics Sonochemistry, vol. 8, no. 3, pp. 299-301, 2001.

[21] M. D. Macías-Sánchez, C. M. Serrano, M. R. Rodríguez, E. M. de la Ossa, L. M. Lubián, and O. Montero, "Extraction of carotenoids and chlorophyll from microalgae with supercritical carbon dioxide and ethanol as cosolvent," Journal of Separation Science, vol. 31, no. 8, pp. 1352-1362, 2008.

[22] S. Sporring, S. Bøwadt, B. Svensmark, and E. Björklund, "Comprehensive comparison of classic Soxhlet extraction with Soxtec extraction, ultrasonication extraction, supercritical fluid extraction, microwave assisted extraction and accelerated solvent extraction for the determination of polychlorinated biphenyls in soil," Journal of Chromatography A, vol. 1090, no. 1-2, pp. 1-9, 2005. 
[23] L. Casas, C. Mantell, M. Rodríguez, A. Torres, F. A. Macías, and E. J. Martínez de la Ossa, "Supercritical fluid extraction of bioactive compounds from sunflower leaves with carbon dioxide and water on a pilot plant scale," Journal of Supercritical Fluids, vol. 45, no. 1, pp. 37-42, 2008.

[24] El catálogo fundamental de Cromatografía de Agilent, Guía completa de referencia para columnas y consumibles, 2008-2009.

[25] K. Helrich, Official Methods of Analysis of the AOAC, AOAC International, Arlington, Va, USA, 15th edition, 1990.

[26] E. Hernández-Martín and C. Otero, "Different enzyme requirements for the synthesis of biodiesel: Novozym 435 and Lipozyme TLIM," Bioresource Technology, vol. 99, no. 2, pp. 277286, 2008.

[27] P. K. Sahoo and L. M. Das, "Process optimization for biodiesel production from Jatropha, Karanja and Polanga oils," Fuel, vol. 88, no. 9, pp. 1588-1594, 2009.

[28] F. Ma, L. D. Clements, and M. A. Hanna, "The effects of catalyst, free fatty acids, and water on transesterification of beef tallow," Transactions of the American Society of Agricultural Engineers, vol. 41, no. 5, pp. 1261-1264, 1998.

[29] B. Freedman, E. H. Pryde, and T. L. Mounts, "Variables affecting the yields of fatty esters from transesterified vegetable oils," Journal of the American Oil Chemists Society, vol. 61, no. 10, pp. 1638-1643, 1984.

[30] B. Liu, G. Cao, and W. Wu, "Preparing biodiesel oil by catalyzing lard with solid alkali," Acta Energiae Solaris Sinica, vol. 33, no. 8, pp. 1279-1282, 2012.

[31] M. Mittelbach, "Advances in biodiesel catalysts and processing technologies," in Advances in Biodiesel Production: Processes and Technologies, pp. 133-153, Elsevier, 2012. 

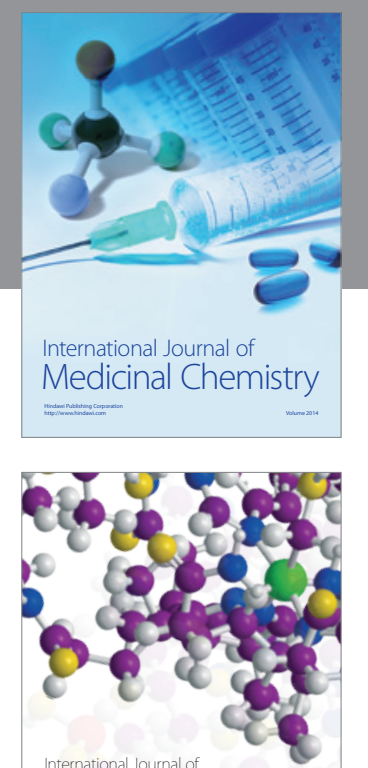

\section{Carbohydrate} Chemistry

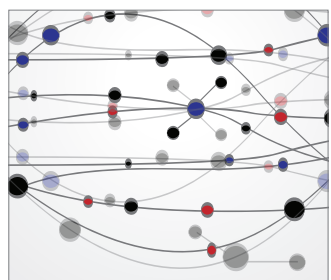

The Scientific World Journal
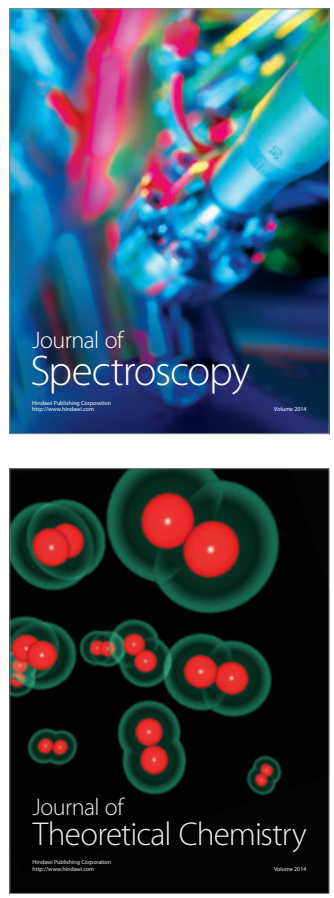
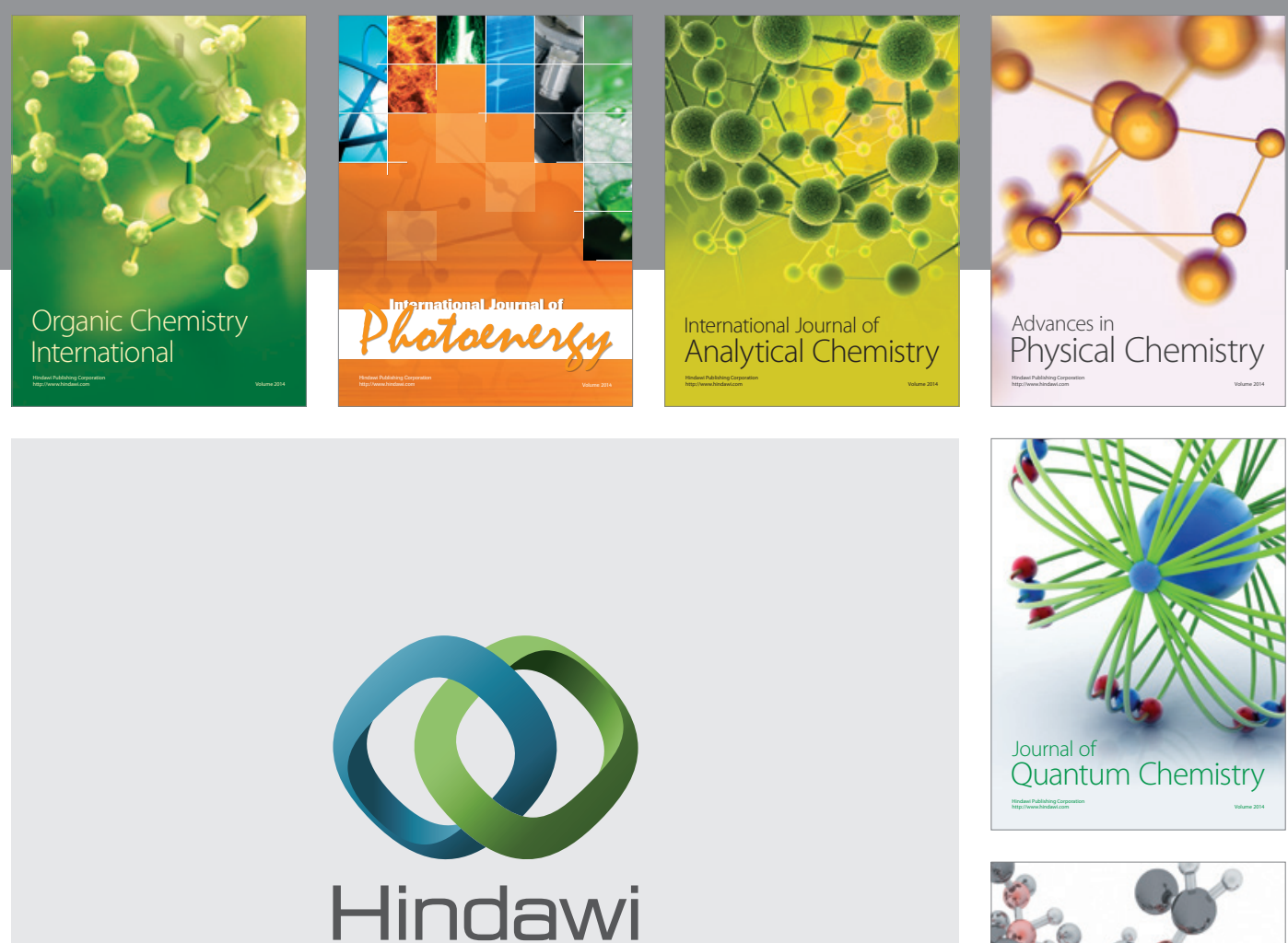

Submit your manuscripts at

http://www.hindawi.com

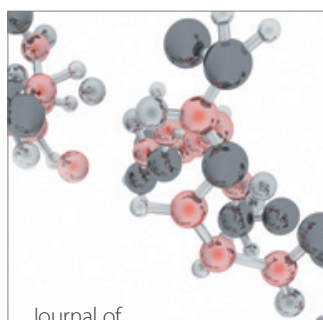

Analytical Methods

in Chemistry

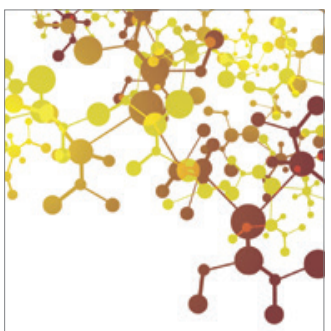

Journal of

Applied Chemistry

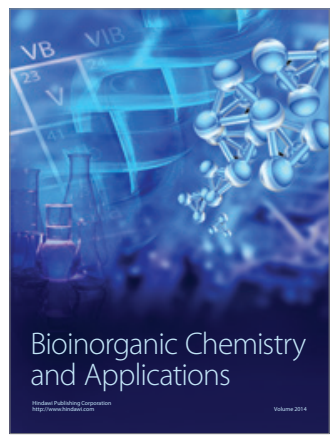

Inorganic Chemistry
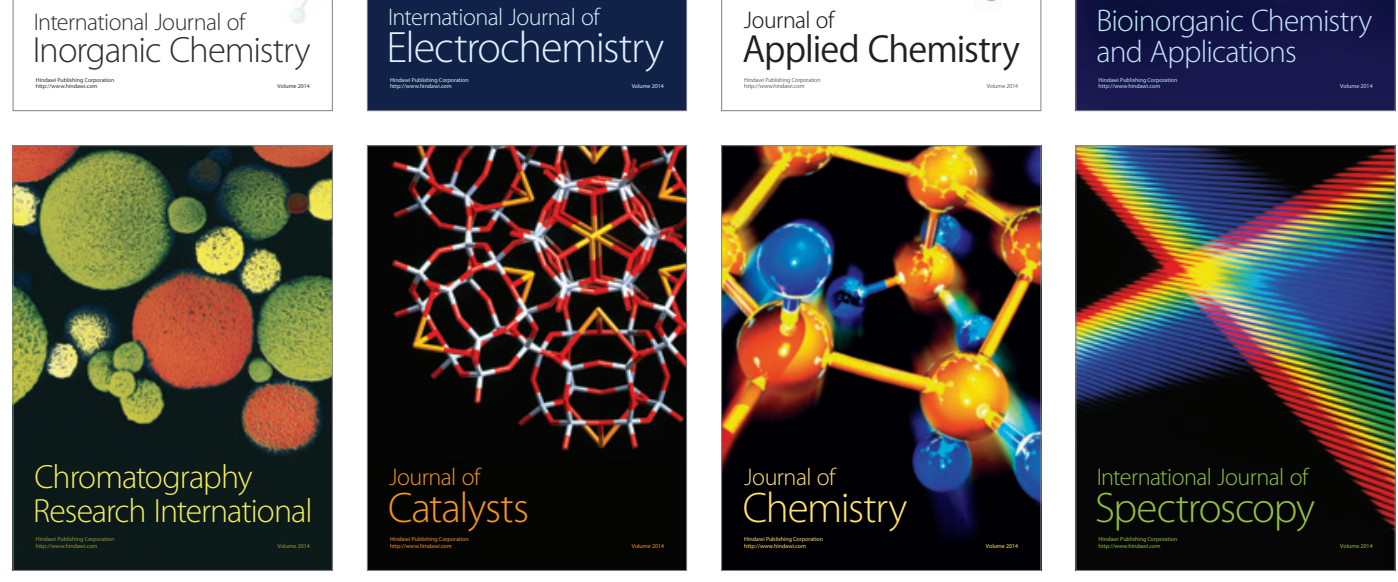